\title{
Anti-Schistosomal activity of five plant extracts on Swiss white mice infected with Schistosoma mansoni
}

\author{
Naomi Waiganjo ${ }^{1,3}$, Yole $\mathrm{D}^{1,3}$, Ochanda $\mathrm{H}^{2}$ \\ Technical University of Kenya, P.O BOX 52428-00200, Nairobi, Kenya \\ University of Nairobi, P.O BOX 30197-00100, Nairobi, Kenya \\ Institute of Primate Research, P.O BOX 24481-00502, Karen, Nairobi, Kenya
}

\begin{abstract}
Schistosomiasis in humans is a major public health problem worldwide. Schistosomiasis occurs in 76 tropical countries and it is estimated that $85 \%$ of the infections are in Africa. In Kenya, it is estimated that 3 million people are infected. The Conventional drugs are effective in the treatment of the disease but very little progress has been achieved on treatment of Schistosomiasis in Kenya. Any effort towards developing alternative drugs for the disease is worthwhile. Praziquantel is the most effective drug against all adult stages of human Schistosomiasis, being the drug of choice for morbidity control of Schistosomiasis. However it is not a satisfying situation to have one drug used for the treatment. Ideally other drugs should be availed in order to avoid development of drug resistance. The use of plant extracts in treatment of diseases is universal. The results obtained showed that Ocimum americanum and Bridelia micrantha plant extracts had antischistosomal activity as indicated by high worm reduction and reduced gross pathology. Histopathology showed no or few granuloma in the liver tissue. Further work should be done on the efficacious extracts, towards drug development.
\end{abstract}

Keywords: Antischistosomal activity, Pathology, Plant extracts, Praziquantel, Schistosomiasis

\section{INTRODUCTION}

Schistosomiasis, like many tropical diseases, is endemic in areas where poor living conditions and poverty are prevalent and deaths are associated with the severe consequences of infection (1).Praziquantel is generally considered the drug of choice for treatment of Schistosomiasis (2). The treatment objective is to cure the disease and to prevent the evolution of infected patients to the chronic form of the disease (3). Many drugs have originated from biologically active plant chemicals, and many plants' medicinal uses can be attributed to various active chemicals found in them $(\mathbf{4}, \mathbf{5})$. Frequency of quote is an important indicator of the usage of the plants by the community. However, information obtained from the community may not always be reliable. It is possible that people may quote a particular plant more frequently since it is easily available, easily recognizable or resembles a certain disease $(6,7)$. The aim of this study was to determine antischistosomal activity of the five plant extracts and identify efficacious extracts in infected white Swiss mice.

\subsection{Plants materials extraction}

\section{MATERIALS AND METHODS}

Sonchus luxurians (whole plant), Ocimum americanum (whole plant), Bridelia micrantha (bark), Croton megalocarpus (bark) and Aloe secundiflora (whole plant) were collected and placed in plastic bags. The plants were dried at room temperature for 2 months and crushed into tiny particles and ground to powder form. The ground plant material for each plant was divided into equal portions and separately placed in clean large container. The mode of extraction naturally depends on the texture and water content of the plant materials being extracted or the type of substances to be isolated. The powdered materials were soaked in various solvents namely hexane, Dichloromethane/ Methanol in ratio of 1:1 and extraction carried out in a Rotary evaporator. The residues were soaked in distilled water then filtered and subjected to freeze drying to constitute the aqueous extract.

The plant extracts obtained were as follows; OAH- Ocimum americanum hexane extract, OADOcimum americanum Dichloromethane /methanol extract DCM, OAW- Ocimum americanum water extract, OAC-Ocimum americanum crude, BMH- Bridelia micrantha hexane extract, BMD- Bridelia micrantha DCM /Methanol extract, BMW - Bridelia micrantha water extract, BMC- Bridelia micrantha crude, SLD- Sonchus luxurians, DCM /methanol extract, SLW- Sonchus luxurians water extract, SLC- Sonchus luxurians crude. CMW- Croton megalocarpus water extract, CMC- Croton megalocarpus crude, ASW- Aloe secundiflora water extract and ASC - Aloe secundiflora crude. 


\subsection{Parasite}

Schistosoma mansoni isolate used in this study was from infected baboons at the Institute of Primate Research (IPR), Karen, and Nairobi, Kenya and maintained in Biomphalaria pfeifferi snails collected from Mwea in Kirinyaga, Kenya. The snails were placed individually in each well of a 24-culture plate. Each snail was infected with 3-6 miracidia. The miracidia were left for 30 minutes to penetrate the snail. The infected snails were placed in plastic tanks containing un-chlorinated water (snail water), sterilized sand and pebbles. Daphnea were included for aeration. The snails were fed on dried lettuce and maintained at the IPR Malacology laboratory. Four weeks post-infection, the snails were covered with a dark cloth to prevent shedding of cercariae. Five weeks after infection, snails were placed under strong light to induce shedding of cercariae for mice infection.

\subsection{Definitive host}

The Swiss mice were obtained from the Kenya Medical Research Institute, Nairobi, Kenya and maintained in IPR at Rodent house at Animal Science Department and housed in cages, in groups of twenty per cage.

\subsection{Infection of mice with Schistosoma mansoni}

The mice to be infected with $S$. mansoni were anaesthetized using $0.02 \mathrm{ml} \mathrm{Ketamine/Rompum} \mathrm{mixture}$ (ratio of 3:1) after been divided into eighteen categories of 12 mice each. Each mouse received approximately 200 cercaria of $S$. mansoni through intact skin penetration by abdominal skin exposure using ring method (Smithers and Terry, 1965). Treatment was done at week 4 post-infection with two doses two days apart. Each dose was $150 \mathrm{mg} / \mathrm{kg}$ body weight of each of the plant extracts. There were three control groups; one was treated with $900 \mathrm{mg} / \mathrm{kg}$ body weight of Praziquantel (8) and the other was infected and then naive group.

\subsection{Perfusion, Worm Recovery, Gross pathology}

At week 6 the abdominal cavity of various mice were opened. The gross pathology of the liver was observed in terms of: inflammation, adhesions and presence of granulomas. Granulomas appear as raised pinheads sized foci distributed over the surface of the liver lobes. Severity of the granulomas was categorized as follows: 1-3 granulomas per lobe were considered few, 4-10, moderate and $\geq 10$ severe. The mice were perfused using the modified method of $(\mathbf{9}, \mathbf{1 0})$. The perfusate was collected in a $20 \mathrm{~cm}$ glass Petri-dish. The perfusate containing the recovered worms were transferred into urine jar and topped with phosphate buffered saline (PBS). After the worms had settled, the supernatant was sucked out, and the settling procedure repeated three times. When the supernatant was clear, the worms were then placed on a Petri dish containing phosphate buffered saline (PBS) and then counted. Any worm still left in the mesenteries/ liver were recovered by soaking the mouse in a Petri dish containing PBS for at least 1h, to allow the worms to crawl out. Percentage reduction for each group was calculated as shown in the formulae below.

\section{Percentage worm reduction $=$ \\ Mean of worms from the IC - the mean of worms from the experimental group $x 100$ The mean of worms from the IC}

\subsection{Worm Reduction}

\section{RESULTS}

There was no significant difference between Praziquantel- PZQ (75.2\%) and the following plant extracts groups: Ocimum americanum hexane - OAH (68.7\%), Bridelia micrantha water extract- BMW (63.4\%), Ocimum americanum water -OAW (61.6\%), Ocimum americanum crude OAC (52\%) and Bridelia micrantha hexane BMH $(48.7 \%)$ at $(\mathrm{p}>0.05)$ as shown in the fig. 1 below. When Infected Control-IC was compared with $\mathrm{OAH}, \mathrm{BMW}, \mathrm{OAW}, \mathrm{OAC}$ and BMH showed significant difference (ANOVA; $<<0.001$ ). However there was no significant difference between IC and Ocimum americanum Dichloromethane /methanol - OAD (48.3\%), Croton megalocarpus water - CMW (47.7\%), Sonchus luxurians Dichloromethane /methanolSLD (46.3\%), Bridelia micrantha Dichloromethane /methanol- BMD (42\%), Croton megalocarpus crude -CMC (38.7\%), Sonchus luxurians water - SLW (36.3\%), Aloe secundiflora water -ASW (34.2\%), Aloe secundiflora crude - ASC (30.9\%) Bridelia micrantha crude - BMC (30.6), Sonchus luxurians crude-SLC (24.2) treatment groups (ANOVA; $\mathrm{p}>0.05$ ). These plant extracts were similar to IC indicating low worm reduction percentage. Similar results were obtained when the experiments were repeated. 


\subsection{Gross pathology}

There was granuloma pathology reduction when PZQ was compared with OA and BM, they was showing no or few granulomas as shown in fig 2. When IC was compared with AS, CM and SL treatment groups were showing moderate and severe granulomas which were an indication of worst pathology as shown in fig 3.PZQ was showing the least pathology.

\subsection{Histopathology}

When PZQ $(7.05 \mu \mathrm{m})$ was compared in terms of granuloma sizes with IC $(22.9 \mu \mathrm{m})$, BMH $(17.3 \mu \mathrm{m})$, CMC (22.2), SLC (17.8 $\mu \mathrm{m})$, SLD $(20.9 \mu \mathrm{m})$, SLW (21. $\mu \mathrm{m}$ 5), ASC $(18.4 \mu \mathrm{m})$ and ASW $(17.7 \mu \mathrm{m})$ there was significant difference (ANOVA; $\mathrm{p}<0.001$ ) as shown in fig. 4. When IC was compared with the following plant extracts; OAH $(11.3 \mu \mathrm{m})$, BMW $(10.8 \mu \mathrm{m})$ and OAW $(11.9 \mu \mathrm{m})$ there was significant difference (ANOVA; $\mathrm{p}<$ $0.001)$

\section{DisCUSSION}

Different treatment groups had different worm reductions. The plant extracts which were significant similar to Praziquantel (ANOVA; p >0.05) were OAH BMW, OAW, CMW, CMC and BMH had high percentage worm reduction when compared with other groups. However, OAH, BMW, OAW, were close to PZQ in terms high worm reduction demonstrating that they were able to protect the mice from schistosomiasis infection. There was significant difference (ANOVA; p<0.001) between, PZQ ,IC and the other treatment groups; OAC, OAD, SLD, BMD, SLW, ASW, SLC, ASC and BMC implying that they were not protective. PZQ has good efficacy against the adult $S$. mansoni worm (11). Gross pathology was focused on the general and overt appearance of the liver. The liver of PZQ compared with IC showed PZQ had few or no granuloma which means that there were few or no worms. On other hand the results of IC indicated moderate and severe granuloma due to heavy worm burden. When IC was compared with plant extracts; OAH, BMW OAW and OAC there was significant difference. This means that those treatment groups were able to fight infection, in similar manner to PZQ. On the other hand when IC was compared to the following plant extracts; SHC, SHD, SHW, ASC, ASW, CMC, CMW, BMD, BMH, BMC there was no difference. This means that the extracts were not protective. The number of granulomas is correlated with number of eggs, which is in turn correlated with number of worms (12). The sizes of granuloma of the five plant extracts varied in sizes. When IC was compared with PZQ, there was a significant difference. Granuloma sizes of PZQ, OAH, and OAW were small compared with IC. This indicated that reduced sizes resulted to reduced disease (13). The rest of plants extracts was significantly similar to IC in term of the sizes.

\section{CONCLUSION}

The plant extracts which was closest to Praziquantel in protective activity were Ocimum americanum hexane, Bridelia micrantha water and Ocimum americanum water indicating their antischistosomal activities. The best plant extracts with no or few granulomas were same plant extracts which is supported by high worm reduction and reduced gross pathology. The reduced granuloma sizes were also indicated on the same plants resulting to reduced disease.

\section{REFERENCES}

[1] World Health Organization. First WHO report on neglected tropical diseases 2010: working to overcome the global impact of neglected tropical diseases? 2010 (1)

[2] Hotez ,PJ. Mass Drug administration and integrated control for the world's high-prevalence neglected tropical diseases. Clinical Pharmacology \& Therapeutics; 85: $2009,659-664 .(2)$

[3] Utzinger J,Keiser J, Shuhua X, Tanner M and Singer, B.H . Combination chemotherapy schistosomiasis in laboratory studies and clinical trials. Antimicrobial Agents Chemotherapy; 47.2003,487-1495.(3)

[4] World Health Organization. Traditional Medicine Strategy 2002-2005. World Health Organization, Geneva. 2002.(4)

[5] Bah, S, Jager, A.K, Adsersen A, Diallo D, Paulsen, B.S. Ethnopharmacological uses of Erythrina senegalensis; a comparison of three areas in Mali and a link between traditional knowledge and modern biological Science. Journal of Ethnopharmacology; 110 (3), 2008, 451-457.(5)

[6] World Health Organization. General guidelines for methodologies on research and evaluation of traditional medicine. World Health Organization, Geneva.2000. (6)

[7] Weiss, R.F.Herbal Medicine, (Beaconsfield Publishers Ltd. Beaconsfield, UK. 1985). (7)

[8] Muchirah, P.N, Yole, D.S, Kutima H, Waihenya R, Kuria, K.M and Mokua J. Determination of effective praziquantel dose in different mouse strains: BALB/c and Swiss mice in treatment of schistosoma mansoni. Journal of Clinical Immunology and Immunopathology Research; 4(2), 2012, 12-21.(8)

[9] Smithers, S.R, Terry, R.J. The Infection of laboratory hosts with the cercariae of S. mansoni and recovery of adult worms. Journal of Parasitology. $55,1965,695-700 .(9)$

[10] Yole, D.S, Obanda, V.O, Kithome K, Ochanda, H. The effect of vaccinating S. mansoni-infected BALB/c mice either before or after treatment. Africa Journal of Health Sciences; 13, 2006, 55-68. (10)

[11] Utzinger, J., Xiao, S.H. , N'Gorah , E.K., Bergquist, R. and Tanner , M . The potential of Artemether for the control of Schistosomiasis. International Journal of Parasitology 31. 2001,1549 - 1562.(11) 
[12] Vennervald Dunne, D.W., Butterworth, A.E., Kariuki, H.C., Kadzo, H., Ireri, E., Amaganga, C., Kimani, G., Kenty, L., Mwatha, J. and Booth, B.J. Periportal fibrosis in human Schistosoma mansoni infection is associated with low IL-10, low IFN-gamma, high TNF- alpha, or low rates, depending on age and gender. Journal of Immunology 15. 2004,1295-303. (12)

[13] Stadecker, M.J. and Colley, D.G. Immunology of schistosome egg granuloma. Parasitology Today; vol.8 no.7. 1992.(13)

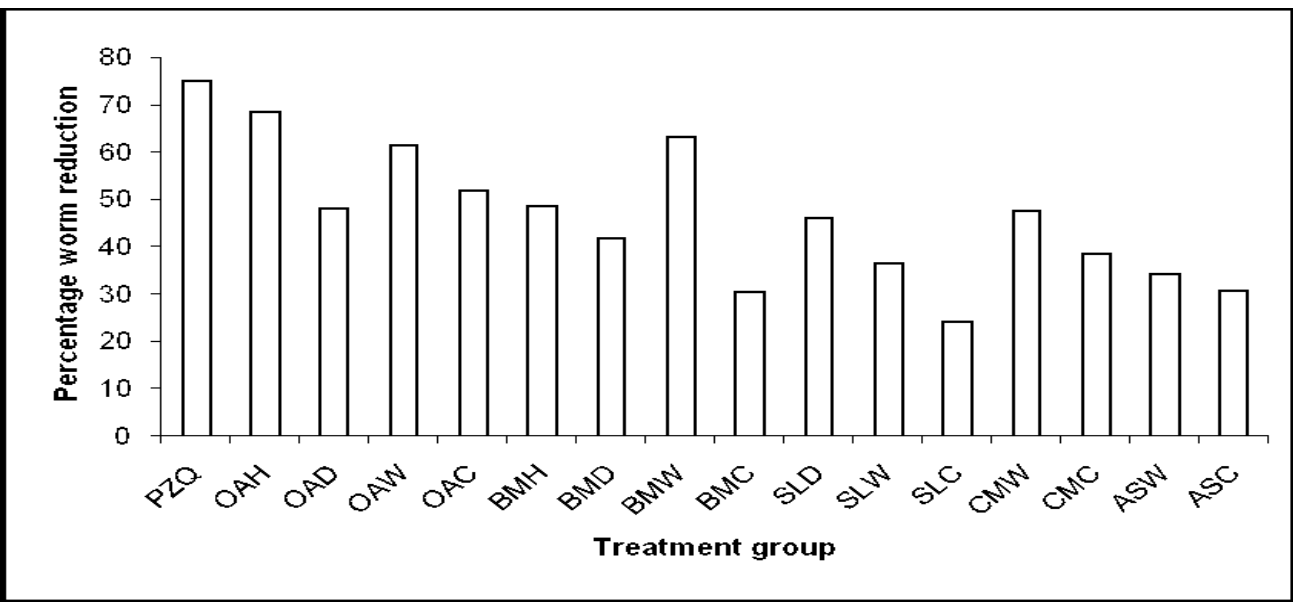

Figure 1: Percentage worm reduction of the five plant extracts
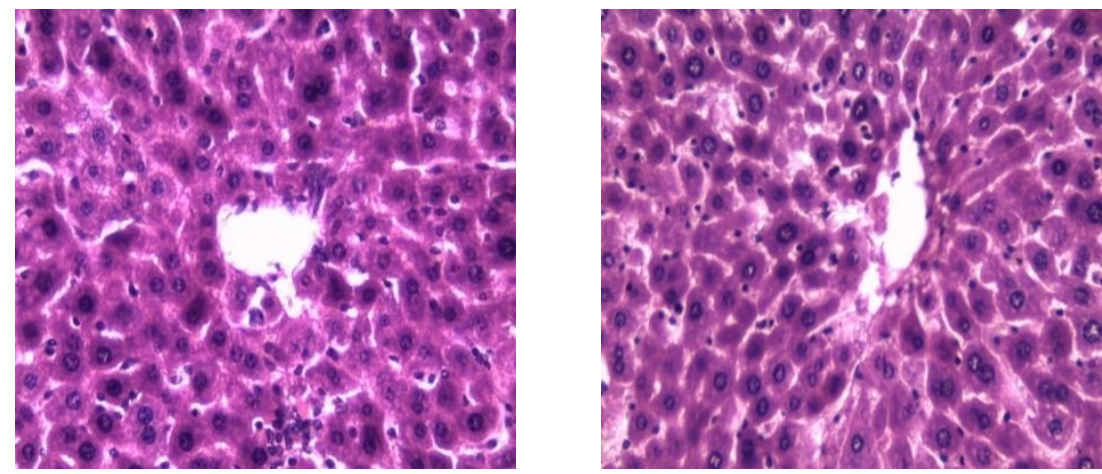

Figure 2: liver sections of Ocimum americanum hexane plant extract (A) and Praziquantel (B) were showing no granuloma.
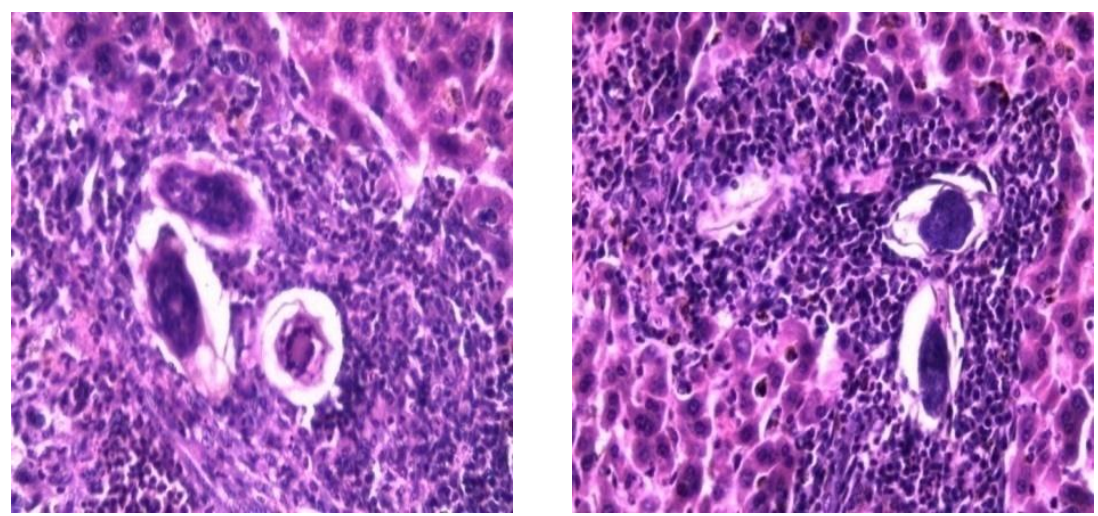

Figure 3: liver tissues sections were showing a granuloma with three eggs for Infected Control (C) and two eggs for ASC (D). 


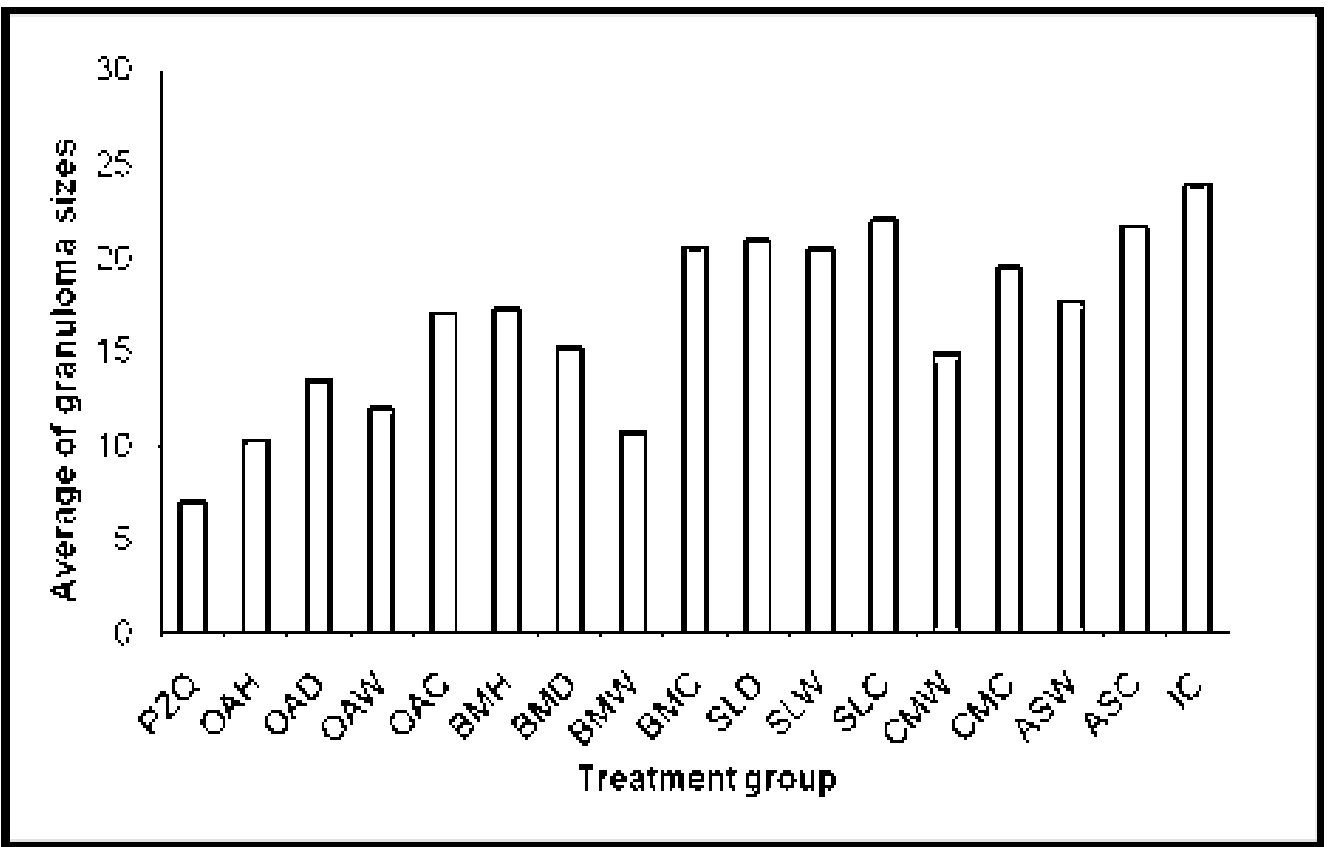

Key:

Figure 4: Size of granuloma in liver tissue for the plant extracts

PZQ- Praziquantel OAH- Ocimum americanum hexane extract OAD- Ocimum americanum Dichloromethane/methanol extract OAWOcimum americanum water extract OAC- Ocimum americanum crude BMH- Bridelia micrantha hexane extract

BMD- Bridelia micrantha Dichloromethane/methanol extract BMW- Bridelia micrantha water extract BMC- Bridelia micrantha crude SLD- Sonchus luxurians Dichloromethane/methanol extract SLW- Sonchus luxurians water extract SLC- Sonchus luxurians crude CMWCroton megalocarpus water extract CMC-Croton megalocarpus crude ASW-Aloe secundiflora water extract ASC - Aloe secundiflora crude IC - infected control 